\title{
A Pigovian Approach to Liquidity Regulation*
}

\author{
Enrico Perotti ${ }^{\mathrm{a}}$ and Javier Suarez ${ }^{\mathrm{b}}$ \\ ${ }^{a}$ University of Amsterdam, De Nederlandsche Bank, \\ and Duisenberg School of Finance \\ ${ }^{\mathrm{b}} \mathrm{CEMFI}$ and CEPR
}

This paper discusses liquidity regulation when short-term funding enables credit growth but generates negative systemic risk externalities. It focuses on the relative merit of price versus quantity rules, showing how they target different incentives for risk creation.

When banks differ in credit opportunities, a Pigovian tax on short-term funding is efficient in containing risk and preserving credit quality, while quantity-based funding ratios are distortionary. Liquidity buffers are either fully ineffective or similar to a Pigovian tax with deadweight costs. Critically, they may be least binding when excess credit incentives are strongest.

When banks differ instead mostly in gambling incentives (due to low charter value or overconfidence), excess credit and liquidity risk are best controlled with net funding ratios. Taxes on short-term funding emerge again as efficient when capital or liquidity ratios keep risk-shifting incentives under control. In general, an optimal policy should involve both types of tools. JEL Codes: G21, G28.

\section{Introduction}

The recent crisis has provided a clear rationale for the regulation of banks' refinancing risk, a critical gap in the Basel II framework. This

${ }^{*}$ We have greatly benefited from numerous discussions with academics and policymakers on our policy writings on the regulation of liquidity and on this paper. Our special thanks to Viral Acharya, Max Bruche, Willem Buiter, Oliver Burkart, Douglas Gale, Charles Goodhart, Nigel Jenkinson, Laura Kodres, Arvind Krishnamurthy, David Martinez-Miera, Rafael Repullo, Jeremy Stein, and ErnstLudwig von Thadden for insightful suggestions and comments. Contact e-mails: e.c.perotti@uva.nl, suarez@cemfi.es. 
paper studies the effectiveness of different approaches to liquidity regulation.

The basic trade-off of short-term funding is that rapid expansion of credit may only be funded by attracting short-term funding (for instance, because deposit supply can be expanded only slowly, or because short-term market lenders do not need to be very informed about new credit choices), but this creates refinancing risk, especially in situations where there are doubts about banks' fundamental solvency or evidence of excessive risk taking on the asset side as well. ${ }^{1}$ Sudden withdrawals may lead to disruptive liquidity runs (Diamond and Dybvig 1983), and cause fire sales or counterparty risk externalities which affect other intermediaries exposed to short-term funding (Brunnermeier 2009; Allen, Babus, and Carletti 2010). As a result, each bank's funding decision has an impact on the vulnerability of other banks to liquidity risk, causing a negative externality. Even if an individual bank's funding decision takes into account its own exposure to refinancing risk, it will not internalize its systemwide effect (Perotti and Suarez 2009). Because of the wedge between the net private value of short-term funding and its social cost, banks will rely excessively on short-term funding. A prime example is the massive build-up in wholesale funding which supported the recent securitization wave, and the overnight credit (repo) growth during 2002-07, which grew explosively to a volume over ten trillion dollars (Gorton 2009).

In the tradition of externality regulation led by Weitzman (1974), we assess the performance of Pigovian taxes (aimed at equating private and social liquidity costs) and quantity regulations in containing this systemic externality. As in Weitzman, the optimal regulatory tool depends on the response elasticity of banks, recognizing that the regulator is informationally constrained in targeting individual bank characteristics. ${ }^{2}$ Our results show how the industry response

\footnotetext{
${ }^{1}$ In this paper, we adopt the same strategy as the Basel Committee on Banking Supervision (BCBS) and, for simplicity, discuss liquidity risk as if it were distinct and separable from other sources of risk. Arguably, liquidity risk and solvency risk are hardly separable, both in practice, as it is hard to tell apart insolvent banks from those with pure liquidity problems, and conceptually, since solvency concerns are at the root of most liquidity crises.

${ }^{2}$ Our analysis is also related to the classical discussion by Poole (1970) on the optimality of price or quantity monetary policy instruments when the system to regulate is affected by several types of shocks. For an earlier discussion on price vs. quantity regulation in banking, see Keeton (1990).
} 
to regulation depends on the composition of bank characteristics. The model recognizes that banks differ in their credit ability and their incentives to take risk. Banks earn decreasing returns to expand credit to their (monitored) borrowers, so better banks naturally lend more. Shareholders of less-capitalized banks gain from investing in poor gambles, since they retain the upside and shift downside risk to the public safety net. ${ }^{3}$ Depending on the dominant source of heterogeneity, the socially efficient solution may be attained with Pigovian taxes, quantity regulations, or a combination of both.

To facilitate the discussion, we first analyze the impact of regulation under either investment-quality or risk-taking heterogeneity. ${ }^{4}$ When banks differ only in capacity to lend profitably (reflecting credit assessment capability or access to credit opportunities), a simple flat-rate Pigovian tax on short-term funding (possibly scaled up by the systemic importance of each bank) implements the efficient allocation. The intuition is that liquidity risk levies allow better banks to lend more, without requiring the regulators to be able to identify them. In this context, quantity-based instruments such as the net stable funding ratio or the liquidity coverage ratio introduced by Basel III (see Basel Committee on Banking Supervision 2010) may improve over the unregulated equilibrium but are generally distortionary. An optimal quantity-based approach would require introducing contingency on individual bank characteristics, most of which are imprecisely measured or unobservable. ${ }^{5}$

More precisely, net stable funding ratios which impose an upper limit on short-term debt do reduce overall liquidity risk but redistribute liquidity risk inefficiently across banks. Banks with better credit opportunities will be constrained, while the reduced systemic

\footnotetext{
${ }^{3}$ An alternative view of gambling incentives is that they are driven by selfinterested and overconfident managers, which view excessive risks as profitable.

${ }^{4}$ Each form of heterogeneity leads to a situation akin to each of the polar cases that Weitzman (1974, p. 485) describes in terms of the "curvature" of the social benefit function and the private cost function relevant to his analysis - he finds that price (quantity) regulation dominates when the social benefit (private cost) function is linear.

${ }^{5}$ Quantity requirements may be indexed to measures of the "systemic importance" of each bank such as those recently considered in regulatory discussions (size, interconnectedness, lack of substitutability, global cross-jurisdictional activity, and complexity), but it is much harder to find good proxies for banks' credit opportunities.
} 
risk actually encourages banks with low credit ability (for which the requirement is not binding) to expand.

Liquidity coverage ratios which require banks to hold fractional reserves of liquid assets against short-term funding work as a de facto tax but one that can turn out to be ineffective or imply large deadweight losses. ${ }^{6}$ When the yield on liquid assets equals the cost of short-term liabilities (roughly the case in normal times, and certainly prior to the crisis), buffers impose no net cost to stacking liquidity. Banks will simply increase their gross short-term funding to keep their "net" short-term funding (i.e., minus the buffers) as high as in the unregulated equilibrium. The only effect is an artificial demand for liquid assets - traditionally kept in money market mutual funds rather than banks - that might be redirected to banks following the new requirement.

When the spread between bank borrowing costs and liquid asset yields is positive, a liquidity requirement operates as a tax on shortterm funding that involves deadweight costs and has its effective tax rate partly determined by market spreads. ${ }^{7}$ In the recent experience, the interbank spread over safe assets was minimal just as aggregate liquidity risk was building up, and it jumped up with the start of the crisis. This means that liquidity requirements would have to be increased in good times and reduced in bad times so as to avoid making them a source of further banking system procyclicality.

Studying variation in risk-shifting incentives (correlated with charter value or another determinant of risk-taking tendencies, such as overconfidence) alters the results radically. Low-charter-value (or more risk-loving) banks have strong incentives to gamble to shift risk to the deposit insurance provider (Keeley 1990). We show that decisions driven by such gambling incentives are not properly deterred by levies, while quantity constraints are more effective. Both shortterm funding limits (e.g., a net stable funding ratio) and capital requirements can contain risk shifting by limiting the scale of lending. Levies will not be as effective as in the previous scenario because the most gambling-inclined banks will also be the most inclined to

\footnotetext{
${ }^{6}$ Liquid assets which can be sold at no fire-sale loss in a crisis are essentially cash, central bank reserves, and treasury bills.

${ }^{7}$ Specifically, the tax rate will equal the product of the buffer requirement per unit of short-term funding times the interest rate spread.
} 
pay the tax and expand their risky lending. In this case, quantity instruments such as net funding or capital ratios are best to contain excess credit expansion.

Our analysis identifies the relative merits of price versus quantity instruments and suggests that combining them may be adequate for the simultaneous control of gambling incentives and systemic risk externalities. However, this presumes that the regulator controls only instruments connected to liquidity risk. If strengthening capital requirements is an effective strategy for the control of gambling incentives (Hellmann, Murdock, and Stiglitz 2000; Repullo 2004), the case for levies on short-term funding is considerably reinforced. ${ }^{8}$

Other considerations may qualify the recommendation for the use of price-based or quantity-based instruments. For instance, levies may be less costly to adjust than ratios. First, they might be easier to change for institutional reasons (e.g., if regulatory ratios are embedded in some law or international agreement while the levies are, at least partly, under control of a macroprudential authority). More importantly, they may imply lower adjustment costs at the bank level than changing bank funding volumes on short notice. Similarly, changes in levies are less likely to induce procyclicality, since the Pigovian "tax rate" is directly controlled by the regulator rather than implicitly set by the interaction of some (controlled) quantitative requirement and the (freely fluctuating) market price of the required resource (namely, capital, liquid assets, or stable funding). For preventive policy, controlling time-varying liquidity risk may then be best achieved by a combination of stable ratios and variable levies.

The rest of the paper is organized as follows. Section 2 describes some related literature and some recent evidence on liquidity risk. Section 3 describes the baseline model. Section 4 characterizes the unregulated equilibrium. Section 5 finds the socially optimal allocation. In section 6 , we discuss the possibility of restoring efficiency with a Pigovian tax on short-term funding. Section 7 considers alternative quantity-based regulations. In section 8 we analyze the

\footnotetext{
${ }^{8}$ Hellmann, Murdock, and Stiglitz (2000) point out that "capital requirements also have a perverse effect of harming banks' franchise values, thus encouraging gambling" but the analysis in Repullo (2004) suggests that the standard deleveraging effect tends to dominate the charter value effect.
} 
implications of introducing gambling incentives as a second dimension of bank heterogeneity. Section 9 discusses further implications and extensions of the analysis. Section 10 concludes the paper.

\section{Evidence from the Crisis and Related Research}

The crisis of 2007-08 has been described as a wholesale bank crisis, or a repo run crisis (Gorton 2009). The rapid withdrawing of short-term debt was responsible for propagation of shocks across investors and markets (Brunnermeier 2009). Brunnermeier and Oemhke (forthcoming) show that creditors have an incentive to shorten their loan maturity, so as to pull out in bad times before other creditors can. This, in turn, causes a lender race to shorten maturity, leading to excessively short-term financing. The consequences are formalized in Martin, Skeie, and von Thadden (2010), where increased collective reliance on repo funding weakens solvency constraints and produces repo runs. Acharya and Viswanathan (2011) model the sudden drying up of liquidity when banks need to refinance short-term debt in bad times. As low asset prices increase incentives for risk shifting, investors may rationally refuse refinancing to illiquid banks.

Acharya, Gale, and Yorulmazer (2011) show that high rollover frequency can reduce the collateral value of risky securities, but they treat debt maturity as exogenous and do not look at the normative implications. Papers emphasizing the possibility of socially inefficient levels of maturity transformation include Huang and Ratnovski (2011), who focus on the deterioration of information production incentives among banks; Farhi and Tirole (2010), where the distortion comes from the expectation of a bail-out; and Segura and Suarez (2011), where the pricing of refinancing during crisis interacts with banks' financial constraints and gives rise to pecuniary externalities linked to banks' funding maturity decisions.

While the role of liquidity risk in the crisis has been evident from the beginning, more precise empirical evidence is now emerging. Acharya and Merrouche (2010) show that UK banks with more wholesale funding and fire-sale losses in 2007-08 contributed more to the transmission of shocks to the interbank market. A concrete measure of the role of short-term debt played in the credit boom, and its demise comes from the explosive rise of repo (overnight) financing in the last years and its rapid deflation since the panic (Gorton 2009). 
Repo funding evaporated in the crisis, leading to bursts of front running in the sales of repossessed securities. Adrian and Brunnermeier (2008) present evidence of the correlation between banks' use of short-term wholesale funding and their proposed measure of banks' contribution to systemic risk (CoVaR). A similar result emerges in Acharya et al. (2010).

The leading causes of external effects from refinancing risk have been identified as losses due to fire sales and collective fears about counterparty risk amplified by simultaneous refinancing choices. They have motivated proposals on the creation of private or public clearing arrangements to limit the effects of runs, though purely private arrangements are not expected to be sufficient in systemic liquidity runs. Acharya and Öncü (2010) argue for the establishment of a Repo Resolution Authority to take over repo positions in a systemic event, paying out a fraction of their claims and liquidating the collateral in an orderly fashion. This would force investors to bear any residual loss. On the opposite front, Gorton (2009) has proposed stopping fire sales of seized collateral by a blanket state guarantee, while Gorton and Metrick (2010) propose creating special vehicles they call narrow banks to hold such assets, backed by a public guarantee.

Another critical issue is the consequences of ex post liquidity bailouts (Farhi and Tirole 2010). The expectation that in a systemic run there is no choice but to provide liquidity to mismatched intermediaries may produce an ex ante moral hazard problem whereby individual institutions take even fewer precautions against crises. This highlights the urgency of measures to contain the private creation of liquidity risk. Finally, systemic crises are the source of important fiscal and real losses not fully internalized by those who make the decisions that lead to the accumulation of systemic liquidity risk (Laeven and Valencia 2010), making a clear case for regulation.

The paper is related to several other strands of the academic literature which would take too long to revise in a systematic manner. These include the corporate finance and banking literatures on the potentially beneficial incentive effects of short-term funding (e.g., Calomiris and Kahn 1991, Diamond and Rajan 2001, and Huberman and Repullo 2010), on the connection between short-term funding and banks' vulnerability to panics and contagion (e.g., Allen and Gale 2000, Rochet and Vives 2004, and Allen, Babus, and Carletti 
2010), and on externalities related to other financial decisions, such as diversification decisions (Wagner 2010) or decisions regarding the supply of credit over the business cycle (Lorenzoni 2008; Jeanne and Korinek 2010). Finally, our analysis is also connected to a vast economic literature about the choice between quantity-based and price-based regulation in specific setups. ${ }^{9}$

\section{The Model}

Consider a one-period model of a banking economy in which all agents are risk neutral. The banking system is made up of a continuum of heterogenous banks run by their owners with the objective of maximizing their expected net present value (NPV). To start with, we assume that banks differ in a parameter $\theta$ that affects the NPV that they can generate using short-term funding, whose amount will be their only decision variable for the time being. ${ }^{10}$ The parameter $\theta$ follows a continuous distribution with positive density $f(\theta)$ over the interval $[0,1]$. Assuming w.l.o.g. that all banks of each class $\theta$ behave symmetrically, the short-term funding decision of each bank of class $\theta$ is denoted by $x(\theta) \in[0, \infty)$.

We postulate that the expected NPV associated with a decision $x$ by a bank of class $\theta$ can be written as

$$
v(x, X, \theta)=\pi(x, \theta)-\varepsilon(x, \theta) c(X),
$$

where $X$ is a measure of the aggregate systemic risk implied by the individual funding decisions of all banks, $\pi(x, \theta)$ is the NPV generated if no systemic liquidity crisis occurs, and $\varepsilon(x, \theta) c(X)$ is the expected NPV loss due to the possibility of a systemic liquidity crisis. To facilitate the presentation, we assume a multiplicative decomposition of the expected crisis losses in two terms: the term $\varepsilon(x, \theta) \geq 0$, which captures the purely individual contribution of the funding decision $x$ and the individual characteristic $\theta$ to the vulnerability of the bank, and the term $c(X) \geq 0$, which captures the influence of other banks' funding decisions on systemic crisis costs.

\footnotetext{
${ }^{9}$ See contributions such as Glaeser and Shleifer (2001) and Kaplow and Shavell (2002) for an overview of the literature.

${ }^{10}$ In section 8 , we introduce a second dimension of bank heterogeneity directed to capture differences in banks' gambling incentives.
} 
We assume that $\pi(x, \theta)$ is increasing and differentiable in its two arguments, strictly concave in $x$, and with a positive cross-derivative, $\pi_{x \theta}>0$, so that a larger $\theta$ implies a larger capability to extract value from short-term funding. To facilitate obtaining interior solutions in $x$ and monotone comparative statics with respect to $\theta$, we also assume that $\varepsilon(x, \theta)$ is differentiable, increasing and weakly convex in $x$, non-increasing in $\theta$, and with $\varepsilon_{x \theta} \leq 0$. Finally, we assume $c(X)$ to be increasing, differentiable, and weakly convex in $X$.

A structural story consistent with this specification might be that $\pi(x, \theta)$ captures the profitability, in the absence of a systemic liquidity crisis, of using short-term funding to expand lending, $\varepsilon(x, \theta)$ captures the probability that the bank faces refinancing problems in a liquidity crisis and has to accommodate them by, say, selling its assets, and $c(X)$ denotes the net liquidation losses incurred in such an event. Notice that $c(X)$ might be increasing in $X$ due to the impact on liquidation values of concurrent sales from troubled banks (e.g., under some cash-in-the-market pricing logic or simply because the alternative users of the liquidated assets face marginally decreasing returns). ${ }^{11}$ Here $\theta$ can be taken as a measure of a bank's credit ability or any other determinant of the marginal net value of its investments.

The key results below would be robust to essentially any specification of the aggregator $X=g(\{x(\theta)\})$, where $\{x(\theta)\}$ is the schedule of the short-term funding used by the banks in each class $\theta \in[0,1]$ and we have $\partial g / \partial x(\theta) \geq 0$ for all $\theta$. For concreteness, however, we focus on the case in which aggregate systemic liquidity risk can be measured as the simple sum of all individual decisions:

$$
X=g(\{x(\theta)\})=\int_{0}^{1} x(\theta) f(\theta) d \theta .
$$

In section 9, we will discuss how to adapt our main results to the case in which banks also differ in a "systemic importance" factor

\footnotetext{
${ }^{11}$ Of course, an increasing $c(X)$ may also partly reflect that $X$ increases the very probability of a systemic crisis. For example, the more vulnerable banks' funding structures are, the more likely it is that asset-side shocks such as a housing market bust or a stock market crash get transformed into a systemic liquidity shock.
} 
that affects the weight of the contribution of their short-term funding to $X$.

We assume that all investors, except bank owners, have the opportunity to invest their wealth at exogenously given market rates and provide funding at competitive terms, hence obtaining a zero NPV from dealing with the banks. Additionally, the model attributes the whole NPV associated with bank investment opportunities to the bank owners, which means that the overall value of the banks to their owners is the natural measure of social welfare $W$ in this economy. To properly interpret this measure, notice that, in reality, banks' investments consist of lending to (or investing in assets issued by) other agents and, in a competitive environment, a significant part of the NPV that constitutes our welfare measure will tend to pass to the borrowers (or the issuers of the assets) through endogenous improvements in lending conditions (or increases in asset prices). We attribute all the gains to the bank owners simply because we abstract from modeling the details of such a pass-through process. Formally, our expression for social welfare is

$$
\begin{aligned}
W(\{x(\theta)\}) & =\int_{0}^{1} v(x(\theta), X, \theta) f(\theta) d \theta \\
& =\int_{0}^{1}[\pi(x(\theta), \theta)-\varepsilon(x(\theta), \theta) c(X)] f(\theta) d \theta .
\end{aligned}
$$

Notice that the short-term funding decision $x$ of any bank of class $\theta$ determines, via $\varepsilon(x, \theta)$, the vulnerability of that very bank to a systemic crisis and also, via $c(X)$, the likelihood and/or costs of a systemic crisis to all other banks.

\section{Equilibrium}

In an unregulated competitive equilibrium, each bank chooses $x$ so as to maximize its own expected NPV, $v(x, X, \theta)$, taking $X$ as given. So an unregulated competitive equilibrium is a pair $\left(\left\{x^{e}(\theta)\right\}, X^{e}\right)$ that satisfies

(i) $x^{e}(\theta)=\arg \max _{x}\left\{\pi(x, \theta)-\varepsilon(x, \theta) c\left(X^{e}\right)\right\}$ for all $\theta \in[0,1]$,

(ii) $X^{e}=\int_{0}^{1} x^{e}(\theta) f(\theta) d \theta$. 
Taking into account the implicit non-negativity constraint on $x$, banks' privately optimal choice of $x$ under given values of $\theta$ and $X$ can be described as the maximum between zero (which corresponds to a corner solution) and the unique solution $y(\theta, X)$ to the first-order condition

$$
\pi_{x}(y(\theta, X), \theta)-\varepsilon_{x}(y(\theta, X), \theta) c(X)=0,
$$

which characterizes an interior solution. Given the assumed properties of the functions involved in this first-order condition, the implicit function theorem implies that $y(\theta, X)$ is increasing in $\theta$ and decreasing in $X .^{12}$

The equilibrium value of $X$ can be found as the fixed point of the auxiliary function $h(X)=\int_{0}^{1} \max \{0, y(\theta, X)\} f(\theta) d \theta$. This function is decreasing in $X$ insofar as $y(\theta, X)>0$ for some positive measure set of values of $\theta$. If we assume $y(1,0)>0$, so that at least the banks with the largest valuation of short-term funding (those with $\theta=1$ ) find it worthy to use some of it if $X=0$, then it is guaranteed that $h(0)>0$ and, by standard arguments, there exists a unique fixed point $X^{e}>0$.

In what follows we will refer to an equilibrium as interior if it satisfies $x^{e}(\theta)>0$ for all $\theta>0$, in which case the first-order condition

$$
\pi_{x}\left(x^{e}(\theta), \theta\right)-\varepsilon_{x}\left(x^{e}(\theta), \theta\right) c\left(X^{e}\right)=0,
$$

with $X^{e}=\int_{0}^{1} x^{e}(\theta) f(\theta) d \theta$, is satisfied for all $\theta \in[0,1]$. Guaranteeing that the equilibrium is interior requires having

$$
\pi_{x}(0,0)-\varepsilon_{x}(0,0) c(X) \geq 0
$$

for a sufficiently large $X$ (e.g., larger than the possibly emerging $X^{e}$ ), so that even the banks with the lowest inclination for short-term funding (those with $\theta=0$ ) want to use some of it in equilibrium. ${ }^{13}$

\footnotetext{
${ }^{12}$ Recall that we have assumed $\pi_{x \theta}>0$ and $\varepsilon_{x \theta} \leq 0$.

${ }^{13} \mathrm{~A}$ sufficient condition for this would be to have $\pi_{x}(0,0)-\varepsilon_{x}(0,0) c(\bar{X}) \geq 0$ with $\bar{X}$ implicitly defined by the equation $\pi_{x}(\bar{X}, 1)-\varepsilon_{x}(\bar{X}, 1) c(\bar{X})=0$, which would characterize the equilibrium value of aggregate systemic risk in the hypothetical scenario in which all banks were of the highest type $\theta=1$. To obtain most of the results below, we need not constrain attention to interior equilibria, but a full discussion of the solutions involving $x(\theta)=0$ for some $\theta$ would make the presentation unnecessarily cumbersome.
} 
As shown below, the presence of systemic risk externalities will make the conditions stated in (5) incompatible with social efficiency.

\section{The Social Planners' Problem}

The socially optimal allocation of short-term funding across banks can be found be maximizing social welfare $W$, taking into account the influence of each individual bank funding strategy on $X$. Formally, a socially optimal allocation can be defined as a pair $\left(\left\{x^{*}(\theta)\right\}, X^{*}\right)$ that satisfies

$$
\begin{aligned}
\left(\left\{x^{*}(\theta)\right\}, X^{*}\right) & \\
=\arg \max _{(\{x(\theta)\}, X)} & \int_{0}^{1}\left[\pi(x(\theta), \theta)-\varepsilon(x(\theta), \theta) c\left(X^{*}\right)\right] f(\theta) d \theta \\
\text { s.t.: } & \int_{0}^{1} x(\theta) f(\theta) d \theta=X^{*} .
\end{aligned}
$$

After substituting the constraint in the objective function, we can find the social optimum by solving the system of equations

$$
\begin{aligned}
\left\{x^{*}(\theta)\right\}= & \arg \max _{\{x(\theta)\}} \int_{0}^{1}[\pi(x(\theta), \theta) \\
& \left.-\varepsilon(x(\theta), \theta) c\left(\int_{0}^{1} x(z) f(z) d z\right)\right] f(\theta) d \theta
\end{aligned}
$$

for $\theta \in[0,1]$, and then finding $X^{*}=\int_{0}^{1} x^{*}(\theta) f(\theta) d \theta$, recursively.

The assumptions adopted in section 3 guarantee the existence of a unique socially optimal allocation. For values of $\theta$ with $x^{*}(\theta)>0$, the first-order condition associated with the maximization in (8) establishes

$$
\pi_{x}\left(x^{*}(\theta), \theta\right)-\varepsilon_{x}\left(x^{*}(\theta), \theta\right) c\left(X^{*}\right)-E_{z}\left(\varepsilon\left(x^{*}(z), z\right)\right) c^{\prime}\left(X^{*}\right)=0,
$$

where $E_{z}\left(\varepsilon\left(x^{*}(z), z\right)\right)=\int_{0}^{1} \varepsilon\left(x^{*}(z), z\right) f(z) d z$. Intuitively, and similarly to the equilibrium allocation, insofar as $x^{*}(\theta)>0$, the socially optimal allocation will assign larger short-term funding to the banks with higher $\theta$. Hence, the socially optimal allocation will be interior if and only if

$$
\pi_{x}(0,0)-\varepsilon_{x}(0,0) c\left(X^{*}\right)-E_{\theta}\left(\varepsilon\left(x^{*}(\theta), \theta\right)\right) c^{\prime}\left(X^{*}\right)>0 .
$$


An interior socially optimal allocation can then be guaranteed if, e.g., the profit function satisfies $\pi_{x}(0,0) \rightarrow \infty$ and the functions $\varepsilon(x, \theta)$ and $c(X)$ have finite derivatives with respect to $x$ and $X$, respectively. ${ }^{14}$

Relative to the conditions for individual bank optimization in an interior equilibrium, given in (5), the conditions in (9) add a third, negative term that reflects the marginal external cost associated with each $x(\theta)$. The marginal external cost relevant for a bank of class $\theta$ is made of two multiplicative factors: the average vulnerability of all the banks in the system to a systemic crisis, $E_{z}\left(\varepsilon\left(x^{*}(z), z\right)\right)$, and the marginal effect of aggregate funding risk on systemic crisis costs, $c^{\prime}\left(X^{*}\right)$.

The presence of the external cost term in (9) implies that any equilibrium allocation $\left\{x^{e}(\theta)\right\}$ with $x^{e}(\theta)>0$ for some positive measure set of $\theta$ s cannot coincide with the socially optimal allocation $\left\{x^{*}(\theta)\right\}$. To see this, notice that if $\left\{x^{e}(\theta)\right\}$ were socially optimal, then, by (9), for any $\theta$ with $x^{e}(\theta)>0$, we should have

$$
\pi_{x}\left(x^{e}(\theta), \theta\right)-\varepsilon_{x}\left(x^{e}(\theta), \theta\right) c\left(X^{e}\right)-E_{z}\left(\varepsilon\left(x^{e}(z), z\right)\right) c^{\prime}\left(X^{e}\right)=0 .
$$

However, the first two terms add up to zero, by (5), while the third term is strictly negative since $E_{z}\left(\varepsilon\left(x^{e}(z), z\right)\right)>0$ and $c^{\prime}\left(X^{e}\right)>0$. So (11) does not hold.

The presence of a negative externality associated with the contribution of banks' short-term funding to aggregate systemic risk suggests that the socially optimal allocation will generally involve a strictly lower level of systemic risk than the equilibrium allocation. Indeed, under the hypothesis that $X^{*} \geq X^{e}>0,(5)$ and (9) would imply that $x^{e}(\theta)>x^{*}(\theta)$ for all $\theta$ with $x^{e}(\theta)>0$ (and $x^{e}(\theta)=x^{*}(\theta)=0$ otherwise), which would obviously mean $X^{e}>X^{*}$ and, hence, would contradict the hypothesis. In practical terms, the results imply that in the unregulated competitive

\footnotetext{
${ }^{14}$ In the same spirit as in the condition given in footnote 4 , an alternative sufficient condition would be to have $\pi_{x}(0,0)-\varepsilon_{x}(0,0) c(\bar{X})-\varepsilon(\bar{X}, 0) c^{\prime}(\bar{X}) \geq 0$ with $\bar{X}$ implicitly defined by the equation $\pi_{x}(\bar{X}, 1)-\varepsilon_{x}(\bar{X}, 1) c(\bar{X})-\varepsilon(\bar{X}, 1) c^{\prime}(\bar{X})=0$, which would characterize the socially optimal level of aggregate systemic risk in the hypothetical scenario in which all banks were of the highest type $\theta=1$. The inequality above uses $\varepsilon(\bar{X}, 0)$ as an upper bound to $E_{\theta}\left(\varepsilon\left(x^{*}(\theta), \theta\right)\right)$, since the vulnerability function $\varepsilon(x, \theta)$ is increasing in $x$ and decreasing in $\theta$.
} 


\section{Figure 1. Unregulated Equilibrium vs. Socially Optimal Allocations}

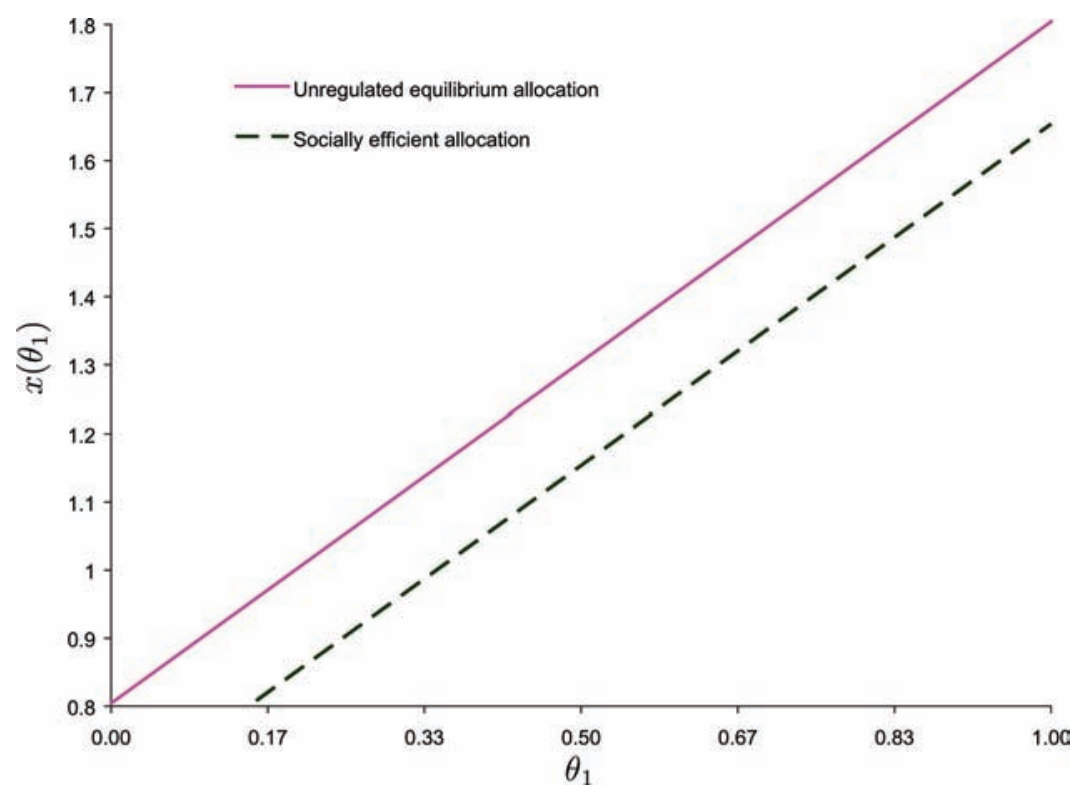

equilibrium, sufficiently many banks (if not all) use more short-term funding than they would use under the socially optimal allocation. ${ }^{15}$ The key insights from this section are summarized in the following proposition.

Proposition 1. The presence of systemic externalities associated with banks' funding decisions, $c^{\prime}(X)>0$, makes the equilibrium allocation socially inefficient and characterized by an excessive aggregate systemic risk $X^{e}>X^{*}$.

Figure 1 depicts the short-term funding decisions that correspond to the unregulated competitive equilibrium and the socially optimal

\footnotetext{
${ }^{15}$ Proving that any $x^{e}(\theta)>0$ is socially excessive given $X^{e}$ is immediate. However, the comparison between $x^{e}(\theta)$ and $x^{*}(\theta)$ for any $\theta$ is more tricky because (5) involves $X^{e}$ while (9) involves $X^{*}<X^{e}$, and the differences between the second terms in each of these first-order conditions create potential ambiguity. In the numerical examples that we have explored, all banks use excessive short-term funding relative to the social optimum.
} 
allocation under a parameterization whose details are easy to work out analytically. $\theta$ is assumed to be uniformly distributed over the $[0,1]$ interval, the profit function is assumed to have the simple quadratic form $\pi(x, \theta)=(1+\theta) x-\frac{1}{2} x^{2}$, and the product of the terms $\varepsilon(x, \theta)$ and $c(X)$ is jointly specified as $\varepsilon(x, \theta) c(X)=\alpha x X$, where $\alpha$ is a positive constant. Interior solutions can be guaranteed for $\alpha<1 / 2$. The figure corresponds to the case with $\alpha=0.15$. The horizontal axis reflects the values of $\theta$ and the vertical axis the unregulated equilibrium and the socially optimal allocations, $x^{e}(\theta)$ and $x^{*}(\theta)$, respectively. The unregulated equilibrium features systemic risk $X^{e}=1.30$ and social welfare $W^{e}=0.892$, while the social optimum features $X^{*}=1.15$ and $W^{*}=0.907$.

Summing up, systemic externalities associated with banks' shortterm funding decisions create a positive wedge between the social and the private marginal costs of using short-term funding. Banks only internalize the implications of the funding choices for their own vulnerability to refinancing risk, disregarding their contribution to all other banks' systemic risk exposure and costs. Standard marginal reasoning when privately optimizing on short-term funding makes systemic risk in the unregulated equilibrium higher than socially optimal.

\section{The Pigovian Tax: An Efficient Solution}

As in the standard textbook discussion on the treatment of negative production externalities, the social efficiency of the competitive equilibrium can be restored by imposing a Pigovian tax, i.e., by taxing the activity causing the externality at a rate equal to the wedge between the social marginal cost and the private marginal cost of the activity (evaluated, if applicable, at the anticipated socially optimal allocation). In our case, this boils down to setting a flat tax per unit of short-term funding equal to

$$
\tau^{*}=E_{z}\left(\varepsilon\left(x^{*}(z), z\right)\right) c^{\prime}\left(X^{*}\right)
$$

Obviously, the introduction of a tax on short-term funding alters the first-order condition relevant for banks' optimization in the competitive equilibrium with taxes. 
Formally, we can define a competitive equilibrium with taxes $\{\tau(\theta)\}$ as a pair $\left(\left\{x^{\tau}(\theta)\right\}, X^{\tau}\right)$ satisfying

(i) $x^{\tau}(\theta)=\arg \max _{x}\left\{\pi(x, \theta)-\varepsilon(x, \theta) c\left(X^{\tau}\right)-\tau(\theta) x\right\}$ for all $\theta \in[0,1]$

(ii) $X^{\tau}=\int_{0}^{1} x^{\tau}(\theta) f(\theta) d \theta$.

In an interior equilibrium, the first-order conditions for the private optimality of each $x^{\tau}(\theta)$ imply

$$
\pi_{x}\left(x^{\tau}(\theta), \theta\right)-\varepsilon_{x}\left(x^{\tau}(\theta), \theta\right) c\left(X^{\tau}\right)-\tau(\theta)=0
$$

for all $\theta \in[0,1]$. And it is immediate to see that the flat tax schedule $\tau(\theta)=\tau^{*}$, with the tax rate defined as in (12), makes (13) equivalent to (9), implying $\left(\left\{x^{\tau^{*}}(\theta)\right\}, X^{\tau^{*}}\right)=\left(\left\{x^{*}(\theta)\right\}, X^{*}\right)$ and, hence, implementing the socially optimal allocation as a competitive equilibrium.

To set the optimal tax rate $\tau^{*}$ properly, it is of course necessary that the regulator knows the functions that characterize the economy (including the density of the parameter $\theta$ that captures banks' heterogeneity) and is, hence, able to compute the socially optimal allocation that enters in (12). For the numerical example shown in figure 1, the flat Pigovian tax that implements the socially optimal allocation as a competitive equilibrium with taxes is $\tau^{*}=$ $0.17 .^{16}$

An important practical difficulty when regulating heterogeneous agents is that the particulars of the regulation applicable to each agent may depend on information that is private to the agent. This problem does not affect the efficient Pigovian $\operatorname{tax} \tau^{*}$, which is the same for all values of $\theta$. The following proposition summarizes the key results of this section.

Proposition 2. When banks differ in the marginal value they can extract from short-term funding, the socially optimal allocation can

\footnotetext{
${ }^{16}$ Of course, this number depends on the underlying parameterization. Without touching other details of our simple example, which was not intended to provide realistic predictions, reducing the parameter $\alpha$ from 0.15 to, e.g., 0.015 reduces the efficient Pigovian tax to $\tau^{*}=0.02$.
} 
be reached as a competitive equilibrium by charging banks a flat Pigovian tax $\tau^{*}$ on each unit of short-term funding.

\section{Quantity-Based and Ratio-Based Alternatives}

Pigovian taxation is frequently described as a price-based solution to the regulation of externalities. Such a description emphasizes the capacity of the tax solution to decentralize the implementation of the desired allocation as a market equilibrium. The polar alternative is to go for a "centralized" quantity-based solution in which each regulated agent (bank) is directly mandated to choose its corresponding quantity (short-term funding) in the optimal allocation $\left(x^{*}(\theta)\right.$ in the model).

In the context of our model, pure quantity-based regulation would require detailed knowledge by the regulator of individual marginal value of short-term funding for each bank (i.e., the derivatives $\pi_{x}(x, \theta)$ and $\varepsilon_{x}(x, \theta)$, which vary with $\theta$ and appear in (9)). Possibly due to the strong informational requirements that this implies, none of the alternatives for liquidity regulation considered in practice these days opt for directly setting individualized quantity prescriptions such as $x^{*}(\theta)$.

The alternatives to Pigovian taxes actually under discussion are ratio-based regulations, i.e., regulations that consist of forcing banks to have some critical accounting ratios above or below some regulatory minima or maxima. To be sure, some proposals include making the regulatory limits functions of individual characteristics of each bank - such as size, interconnectedness, lack of substitutability, global (cross-jurisdictional) activity, and complexity-but none of the considered characteristics seem targeted to control for the heterogeneity in banks' capacity to extract value from short-term funding. ${ }^{17}$ These qualifiers can be rather rationalized as an attempt to capture what, in an extension discussed in section 9 , we describe as the systemic importance of each bank (the relative importance of the contribution of its short-term funding to the systemic risk measure $X$ ).

\footnotetext{
${ }^{17}$ See, for example, the press release on "Measures for Global Systemically Important Banks Agreed by the Group of Governors and Heads of Supervision" issued by the BCBS on June 25, 2011 (see www.bis.org/press/p110625.htm).
} 
The most seriously considered ratio-based alternatives for the regulation of liquidity are those put forward by the new Basel III agreement (see Basel Committee on Banking Supervision 2010). The agreement introduces two new regulatory ratios: a liquidity coverage ratio, similar in format and spirit to one already introduced by the Financial Services Authority in the United Kingdom in October 2009 , and a more innovative net stable funding ratio. To facilitate the discussion, we analyze each of these instruments as if it were introduced in isolation, starting with the last one, whose potential effectiveness for the regulation of funding maturity is somewhat less ambiguous.

\subsection{A Stable Funding Requirement}

The net stable funding requirement calls banks to hold some accounting ratio of "stable funding" (i.e., equity, customer deposits, and other long-term or "stable" sources of funding) to "non-liquid assets" above some regulatory minimum. To translate this to our model, where banks' asset composition and stable sources of funding have been so far treated as exogenously fixed, we can think of this requirement as equivalent to imposing an upper limit $\bar{x}$ to the short-term debt that each bank can issue. In a more general version of our model, the effective upper limit applicable to each bank could be considered affected by prior decisions regarding the maturity and liquidity structure of the bank's assets, its retail deposits base, its level of capitalization, etc. But here, for simplicity, one can think of changes in these decisions as possible interpretations for the comparative statics of $\bar{x}$.

The introduction of a minimum stable funding requirement has then the implication of adding an inequality constraint of the type $x \leq \bar{x}$ to the private optimization problem of the banks. Formally, a competitive equilibrium with a stable funding requirement parameterized by $\bar{x}$ can be defined as a pair $\left(\left\{x^{\bar{x}}(\theta)\right\}, X^{\bar{x}}\right)$ satisfying

(i) $x^{\bar{x}}(\theta)=\arg \max _{x \leq \bar{x}}\left\{\pi(x, \theta)-\varepsilon(x, \theta) c\left(X^{\bar{x}}\right)\right\}$ for all $\theta \in[0,1]$,

(ii) $X^{\bar{x}}=\int_{0}^{1} x^{\bar{x}}(\theta) f(\theta) d \theta$.

Since the preference for short-term funding is strictly increasing in $\theta$, we may have up to three possible configurations of equilibrium. 
For $\bar{x} \geq x^{e}(1)$, the stable funding requirement will not be binding for any bank (since $\theta=1$ identifies the banks with the highest incentives to use short-term funding), and the equilibrium will then coincide with the unregulated competitive equilibrium characterized in section 4 . For $\bar{x} \leq x^{e}(0)$, the stable funding requirement will be binding for all banks (since $\theta=1$ identifies the banks with the lowest incentives to use short-term funding), implying $x^{\bar{x}}(\theta)=\bar{x}<x^{e}(\theta)$ for all $\theta$ and, hence, $X^{\bar{x}}=\bar{x}<X^{e}$. Finally, for $\bar{x} \in\left(x^{e}(0), x^{e}(1)\right)$, the stable funding requirement will be binding for at least the banks with the largest $\theta$ s and perhaps for all banks. To see the latter, notice that inducing the limit choice of $x^{\bar{x}}(\theta)=\bar{x}<x^{e}(\theta)$ to the banks with relatively large $\theta$ s will push $X^{\bar{x}}$ below $X^{e}$, but this, in turn, will push the banks with relatively low $\theta$ s into choices of $x^{\bar{x}}(\theta)>x^{e}(\theta)$, possibly (but not necessarily) inducing some or even all of them to also hit the regulatory limit $\bar{x}$.

It is then obvious that, in general, a sufficiently tight stable funding requirement $\bar{x}<x^{e}(1)$ can reduce the equilibrium measure of aggregate systemic risk $X^{\bar{x}}$ relative to the unregulated equilibrium $X^{e}$, thus moving it closer to its value in the socially optimal allocation $X^{*}$. The induced allocation will, however, be necessarily inefficient. The reason for this is that the reduction in the activities that generate negative externalities comes at the cost of distorting the allocation of short-term funding across bank classes: (i) constraining the banks with relatively higher valuation for shortterm funding to the common upper limit $\bar{x}$, and (ii) encouraging the banks with relatively low valuation for short-term funding to use more of it than would be socially optimal (since they will choose $x^{\bar{x}}(\theta)>x^{e}(\theta)>x^{*}(\theta)$ ). In fact, there is no guarantee that introducing a $\bar{x}$ that simply brings $X^{\bar{x}}$ closer to $X^{*}$ improves, in welfare terms, over the unregulated equilibrium.

Proposition 3. A binding net stable funding requirement will affect the measure of aggregate systemic risk $X$ in the same direction as the efficient arrangement (i.e., will reduce $X$ ), but it will also redistribute short-term funding inefficiently from banks that value it more to banks that value it less, so that the socially optimal allocation cannot be reached and the improvement in social welfare is not guaranteed. 
Assuming a solution in which $\bar{x}$ is binding for some but not all banks, the socially optimal choice of $\bar{x}$ can be defined as follows:

$$
\begin{gathered}
\bar{x}^{S B}=\arg \max _{\left(\bar{x}, X^{\bar{x}}\right)} \quad \int_{0}^{\bar{\theta}}\left[\pi\left(y\left(\theta, X^{\bar{x}}\right), \theta\right)-\varepsilon\left(y\left(\theta, X^{\bar{x}}\right), \theta\right) c\left(X^{\bar{x}}\right)\right] f(\theta) d \theta \\
+\int_{\bar{\theta}}^{1}\left[\pi(\bar{x}, \theta)-\varepsilon(\bar{x}, \theta) c\left(X^{\bar{x}}\right)\right] f(\theta) d \theta \\
\text { s.t.: } \quad \int_{0}^{\bar{\theta}} y\left(\theta, X^{\bar{x}}\right) f(\theta) d \theta+\bar{x}[1-F(\bar{\theta})]=X^{\bar{x}},
\end{gathered}
$$

where the function $y(\theta, X)$ is defined as in $(4)$ and $F(\theta)$ is the cumulative distribution function associated with $f(\theta)$. This problem identifies the "second-best" allocation attainable if the only available instrument for liquidity regulation is the stable funding requirement $\bar{x}$, which is assumed to be binding only for the banks with $\theta \in(\bar{\theta}, 1]$, where $\bar{\theta}$ is implicitly defined by $y\left(\bar{\theta}, X^{\bar{x}}\right)=\bar{x}$.

To solve the problem in (14), the simplest approach is to treat the constraint as a definition of the aggregate systemic risk $X^{\bar{x}}$ induced by the choice of $\bar{x}$, so that $\bar{x}$ is effectively the only decision variable. The first-order condition for an optimal interior solution in this variable will then require that the full differential of the objective function above with respect to $\bar{x}$ is made equal to zero at the optimum $\bar{x}^{S B}$. Such full differential of the objective function will generally have terms related to (i) the direct effects of a marginal variation in $\bar{x}$ on the integrands, (ii) the effects of a marginal variation in $\bar{x}$ on $\bar{\theta}$ (and through it on social welfare), and (iii) the effects of a marginal variation in $\bar{x}$ on $X^{\bar{x}}$ (and through it on social welfare). However, it turns out that the effects of type (i) are only relevant in the second term of the objective function (i.e., for the net value generated by banks for which the stable funding requirement is binding), (ii) is zero, and the effects of type (iii) channelled via $y\left(\theta, X^{\bar{x}}\right)$ for the banks for which the stable funding requirement is not binding are also zero by virtue of (4). ${ }^{18}$

\footnotetext{
${ }^{18}$ This last effect is simply the particularization of the envelope theorem to the individual optimization decisions of unconstrained banks.
} 
Eventually, the only non-zero terms resulting from the full differentiation of social welfare with respect to $\bar{x}$ give rise to the following first-order condition for an interior solution to the maximization problem in (14):

$$
\int_{\bar{\theta}}^{1}\left[\pi_{x}(\bar{x}, \theta)-\varepsilon_{x}(\bar{x}, \theta) c\left(X^{\bar{x}}\right)\right] f(\theta) d \theta-E_{\theta}\left(\varepsilon\left(x^{\bar{x}}(\theta), \theta\right)\right) c^{\prime}\left(X^{\bar{x}}\right) \frac{d X^{\bar{x}}}{d \bar{x}}=0,
$$

where

$$
\frac{d X^{\bar{x}}}{d \bar{x}}=\frac{1-F(\bar{\theta})}{1-\int_{0}^{\bar{\theta}} y_{X}\left(\theta, X^{\bar{x}}\right) f(\theta) d \theta} \in[0,1] .
$$

The first term on the left-hand side of (15) collects the direct effects of a marginal change in $\bar{x}$ on the expected NPV generated by the banks for which the stable funding requirement is binding. This term is positive because, for given $X^{\bar{x}}$, relaxing the constraint associated with $\bar{x}$ would produce more NPV at each constrained bank. The second term captures the impact of the requirement $\bar{x}$ on aggregate systemic risk $X^{\bar{x}}$ and, through it, on the negative externalities suffered by all banks. This term is clearly negative and the only reason why introducing a binding $\bar{x}^{S B}$ may be possibly optimal in a secondbest sense. As reflected in (16), $d X^{\bar{x}} / d \bar{x}$ will typically be lower than one because moving $\bar{x}$ will directly reduce the systemic risk generated by the constrained banks only, while indirectly encouraging (due to the very reduction in $X^{\bar{x}}$ ) the use of short-term funding by the unconstrained banks. ${ }^{19}$

To gain further intuition on the second-best nature of the tradeoffs behind the choice of $\bar{x}^{S B}$, it is convenient to compare (15) with the condition for first-best efficiency in (9). First, (9) applies pointwise, defining an efficient $x^{*}(\theta)$ for each $\theta$; in contrast, (15) determines a common upper limit $\bar{x}$ to the short-term funding decisions of all banks. Hence, in (15) the costs and benefits of marginally moving $\bar{x}$ are "averaged" over all the $\theta$ s. The terms in the integral that appears in (15) resemble the first two terms on the left-hand side of

\footnotetext{
${ }^{19}$ The fact that $y\left(\theta, X^{\bar{x}}\right)$ is decreasing in $X^{\bar{x}}$ follows directly from applying the implicit function theorem on (4).
} 


\section{Figure 2. Equilibrium Allocation under the Best Stable Funding Requirement}

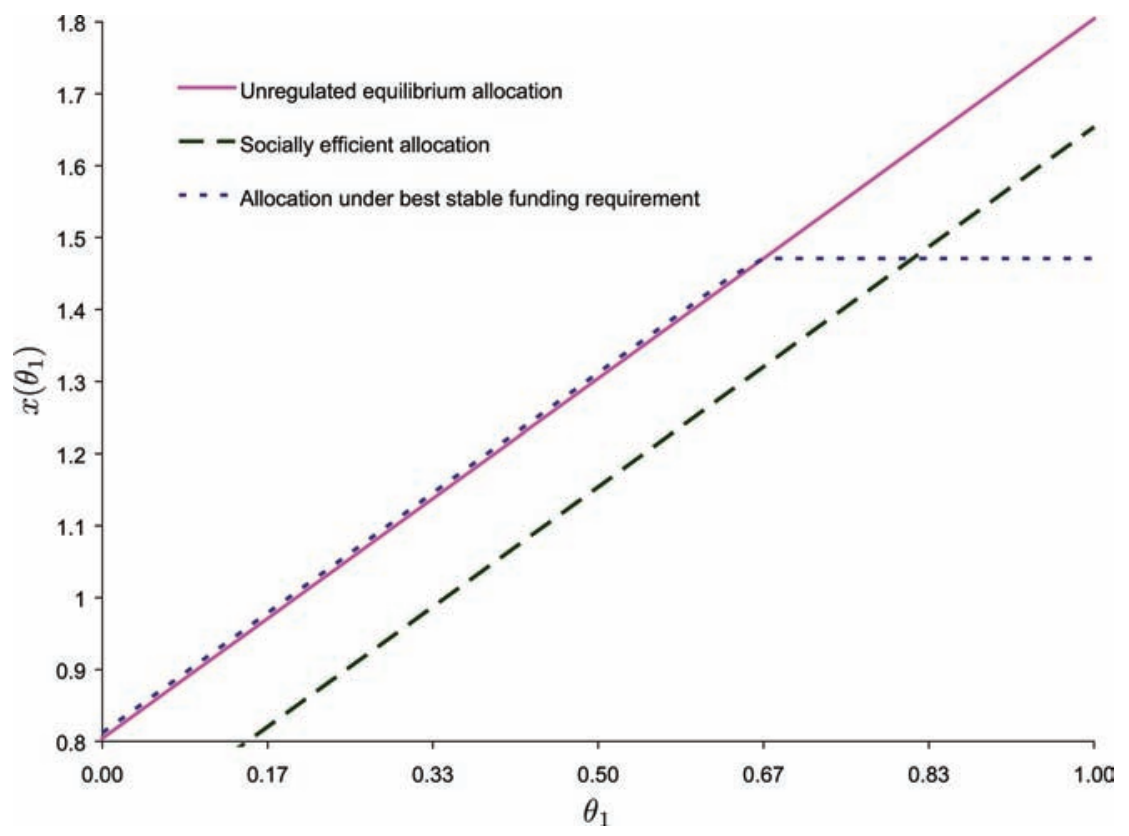

(9), but the ones "averaged" here correspond to the set of high $\theta$ s only, for which the requirement $\bar{x}$ is binding - the remaining banks are not directly affected by $\bar{x}$. The second term in (15) and the third in (9) reflect the marginal externality caused by $\bar{x}$ and each $x^{*}(\theta)$, respectively. The relevant difference regarding these terms is due to the presence of $d X^{\bar{x}} / d \bar{x}$ (typically lower than one) in (15).

Intuitively, the stable funding requirement emerges as just too rough a way to deal with the underlying systemic externalities. It hinges on constraining in a fully indiscriminate manner the decisions made by the banks that, under the source of heterogeneity considered here, are precisely those that can generate more value from short-term funding. And it has the undesirable (though possibly quantitatively small) side effect of encouraging those that generate less value from short-term funding to use more of it. In the numerical example depicted in figure 2, built on the same assumptions as figure 1 , we have that $\bar{x}^{S B}=1.47$, which means the best stable funding 
requirement is binding for the banks in the top 34 percent quantile of the distribution of $\theta$ s. For lower values of $\theta$, the resulting allocation involves some $x^{\bar{x}}(\theta)$ slightly above those in the unregulated equilibrium, $x^{e}(\theta)$, and the whole second-best allocation attainable with $\bar{x}^{S B}$ is quite distant from the socially efficient one, $x^{*}(\theta)$. The best stable funding requirement leads to a social welfare of $W^{\bar{x}}=0.896$ (only 0.4 percent larger than in the unregulated equilibrium), while the optimal flat Pigovian tax reaches the first-best level $W^{*}=0.907$ (1.6 percent more than in the unregulated equilibrium). The best stable funding requirement reduces aggregate systemic risk by 3.9 percent, while the optimal Pigovian tax reduces it by 11.5 percent.

\subsection{A Liquidity Requirement}

The liquidity coverage ratio introduced by Basel III requires banks to back their use of short-term funding with the holding of highquality liquid assets, i.e., assets that could be easily sold, presumably at no fire-sale loss, in case of a crisis. In its original description, this requirement responds to the motivation of providing each bank with its own liquidity buffer, which, presumably, might also expand the liquidity available in the system in case of a crisis (on top of that possibly provided by the lender of last resort).

Specifically, it is proposed that banks estimate the refinancing needs that they would accumulate if the functioning of money markets or other conventional borrowing sources were disrupted for some specified period (one month) and keep enough high-quality liquid assets so as to be able to confront the situation with their sale. ${ }^{20}$ Qualifying assets would essentially be cash, central bank reserves, and treasury bonds.

How can we capture this requirement in the context of our model? Leaving details aside, the liquidity requirement can be seen as a requirement to back some minimal fraction $\phi \leq 1$ of each bank's short-term funding $x$ with the holding of qualifying liquid assets $m$, thereby introducing the constraint $m \geq \phi x$. Additionally, the impact

\footnotetext{
${ }^{20}$ Another option would be to post them as collateral at the central bank's discount window.
} 
of $m$ on the bank's objective function could be taken into account by considering the following extended value function:

$$
v(x, m, X, \theta)=\pi(x-m, \theta)-\varepsilon(x-m, \theta) c(\widehat{X})-\delta m,
$$

where

$$
\widehat{X}=\int_{0}^{1}[x(\theta)-m(\theta)] f(\theta) d \theta
$$

and $\delta=r_{b}-r_{m} \geq 0$ is the difference between the bank's short-term borrowing rate $r_{b}$ and the yield $r_{m}$ of the qualifying liquid assets. This formulation credits for both the individual and the systemic "buffering" role of the liquid assets by making each bank's individual vulnerability factor $\varepsilon(x-m, \theta)$ a function of its net short-term funding and by redefining the systemic risk measure $\widehat{X}$ as the result of aggregating banks' net short-term funding positions.

The other terms in (17) capture the NPV generated in the absence of a systemic crisis. Our formulation is based on assuming that the former function $\pi(x, \theta)$ only captured the NPV generated by the bank's core lending or investment activity, which does not include investing in the qualifying liquid assets. The new first argument of $\pi(x-m, \theta)$ is justified by the fact that if a part $m$ of the resources obtained as short-term funding $x$ is invested in liquid assets, the net amount available for core banking activities becomes $x-m$. We assume that the funds $m$ invested in liquid assets yield a risk-free rate $r_{m}$ but have a cost equal to the bank's short-term borrowing rate $r_{b} \geq r_{m}$, in which, for simplicity, we will treat $r_{b}$ as exogenous (and equal for all banks). ${ }^{21}$ Hence the spread $\delta=r_{b}-r_{m} \geq 0$ acts as a direct net cost of holding liquid assets.

\footnotetext{
${ }^{21}$ In principle, $r_{b}$ should depend on each bank's risk of insolvency as assessed by market participants. In the logic of the model, one might think of the spread as directly connected to $\varepsilon(x-m, \theta)$ and perhaps also to $c(X)$. However, the exogeneity of $r_{b}$ can be justified by alluding either to informational asymmetries or safety-net guarantees that effectively make investors not discriminate across banks. Additionally, one could also argue that the main driver of banks' insolvency risk is asset risk, from which we are abstracting.
} 
In this extended framework, social welfare can be written as

$$
\begin{aligned}
W(\{x(\theta), m(\theta)\})= & \int_{0}^{1}[\pi(x(\theta)-m(\theta), \theta)-\varepsilon(x(\theta)-m(\theta), \theta) c(\widehat{X}) \\
& -\delta m(\theta)] f(\theta) d \theta
\end{aligned}
$$

where the presence of $-\delta m(\theta)$ implies considering banks' direct costs of holding liquidity as a deadweight loss. This formulation is consistent with having assumed that investors provide (short-term) funding to the banks at competitive market rates and thus make zero NPV when doing so. In this context, $\delta>0$ can be interpreted as the premium that compensates investors for (unmodeled) utility losses derived from either the risk or the lower liquidity of their investment in bank liabilities.

A competitive equilibrium with a liquidity requirement parameterized by $\phi$ can be defined as a pair $\left(\left\{\left(x^{\phi}(\theta), m^{\phi}(\theta)\right)\right\}, \widehat{X}^{\phi}\right)$ satisfying

(i) $\left(x^{\phi}(\theta), m^{\phi}(\theta)\right)=\arg \max _{m \geq \phi x}\left\{\pi(x-m, \theta)-\varepsilon(x-m, \theta) c\left(\widehat{X}^{\phi}\right)-\right.$ $\delta m\}$ for all $\theta \in[0,1]$,

(ii) $\widehat{X}^{\phi}=\int_{0}^{1}\left(x^{\phi}(\theta)-m^{\phi}(\theta)\right) f(\theta) d \theta$.

Before continuing, it may be worth commenting on how equilibrium looks in the special limit case with $\phi=1$. Obliging banks to match each unit of short-term funding with one unit of liquid assets implies that banks are left with no funds to expand their valuecreating activities. In other words, banks will have $\widehat{x}=x-m=0$ for any possible choice of $x$. However, any $x>0$ will imply $m=x>0$, and hence paying the corresponding direct cost $\delta m>0$ of holding liquidity, so banks will optimally fix $x=m=0$. Of course, aggregate systemic risk will be zero, i.e., $\widehat{X}^{\phi=1}=0$, but the welfare generated by the banks, as measured by (19), will also be zero. In what follows we will focus on the case with $\phi<1$.

In general the liquidity requirement can be taken as binding (necessarily so if $\delta>0$ and binding without loss of generality if $\delta=0$ ). For $\phi<1$ it is possible and convenient to reformulate banks' optimization problem in terms of their choice of net short-term funding $\widehat{x}(\theta)=x(\theta)-m(\theta)$ only, since the binding liquidity constraint 
allows us to write $m(\theta)$ as $\frac{\phi}{1-\phi} \widehat{x}(\theta)$ and eliminate it as an independent decision variable. Hence, equilibrium can be redefined as a pair $\left(\left\{\widehat{x}^{\phi}(\theta)\right\}, \widehat{X}^{\phi}\right)$ satisfying

(i) $\widehat{x}^{\phi}(\theta)=\arg \max _{\widehat{x}}\left\{\pi(\widehat{x}, \theta)-\varepsilon(\widehat{x}, \theta) c\left(\widehat{X}^{\phi}\right)-\frac{\delta \phi}{1-\phi} \widehat{x}\right\}$ for all $\theta \in[0,1]$

(ii) $\widehat{X}^{\phi}=\int_{0}^{1} \widehat{x}^{\phi}(\theta) f(\theta) d \theta$.

We will proceed with the analysis by looking first at the case in which the net cost of holding liquid assets is zero $(\delta=0)$ and then at the case in which it is positive $(\delta>0)$.

\subsubsection{The Case in which Holding Liquidity Is Costless $(\delta=0)$}

The following proposition establishes a somewhat shocking result for the relevant case in which the spread $\delta$ is zero (roughly the case in "normal times," when banks are perceived as essentially risk-free borrowers).

Proposition 4. With $\delta=0$, the competitive equilibrium with a liquidity requirement $\phi<1$ involves the same amount of net shortterm funding and, hence, the same level of systemic risk as the unregulated equilibrium. That is, it involves $x^{\phi}(\theta)-m^{\phi}(\theta)=x^{e}(\theta)$ and $\widehat{X}^{\phi}=X^{e}$.

The proof of this proposition follows immediately from the equivalence, when $\delta=0$, between the equilibrium conditions for $\left(\left\{\widehat{x}^{\phi}(\theta)\right\}, \widehat{X}^{\phi}\right)$ and those for $\left(\left\{x^{e}(\theta)\right\}, X^{e}\right)$ (see section 4). Hence, the only effect of the liquidity requirement relative to the unregulated equilibrium is to induce an artificial demand $M^{\phi}=\frac{\phi}{1-\phi} E_{\theta}\left(x^{e}(\theta)\right)$ for the qualifying liquid assets and a spurious increase in banks' gross short-term funding, which becomes $E_{\theta}\left(x^{\phi}(\theta)\right)=E_{\theta}\left(x^{e}(\theta)\right)+M=$ $\frac{1}{1-\phi} E_{\theta}\left(x^{e}(\theta)\right)$.

Therefore, when the direct net cost $\delta$ of each unit of liquidity that the requirement forces banks to hold is zero (not implausible in "normal times"), the liquidity coverage ratio totally fails to bring the equilibrium allocation any closer to the social optimum than in the unregulated scenario. Banks respond to regulation by increasing their short-term funding and their liquidity holding so as to make 
their net short-term funding as high as in the unregulated equilibrium. The artificial demand for high-quality liquid assets may imply that liquid assets, kept somewhere else in the financial system (e.g., money market mutual funds) prior to imposing the ratio, end up kept by banks after imposing the ratio. However, the (net) systemic risk generated by the banks will not change.

\subsubsection{The Case in which Holding Liquidity Is Costly $(\delta>0)$}

When the direct net unit cost of holding liquidity, $\delta$, is positive, the implications are quite different. The conditions that characterize $\left(\left\{\widehat{x}^{\phi}(\theta)\right\}, \widehat{X}^{\phi}\right)$ become analogous to those that characterize a competitive equilibrium with taxes in which $\tau(\theta)=\frac{\delta \phi}{1-\phi}$ (see section 6 ). This allows us to directly state the following proposition.

Proposition 5. With $\delta>0$, the competitive equilibrium with a liquidity requirement $\phi<1$ involves the same individual net shortterm funding decisions and aggregate systemic risk as a competitive equilibrium with a tax on short-term funding with rate $\tau(\theta)=\frac{\delta \phi}{1-\phi}$ for all $\theta$.

For a given $\delta>0$, the implicit tax rate $\delta \phi /(1-\phi)$ described above moves from zero to infinity as the liquidity requirement $\phi$ moves from zero to one. Thus the regulator can seemingly replicate the effects of any flat tax $\tau$ (including the efficient Pigovian tax $\tau^{*}$ of section 6) by setting $\phi=\frac{\tau}{\delta+\tau}$. However, banks' demand for the qualifying liquid assets would be $m^{\phi}(\theta)=\frac{\phi}{1-\phi} \widehat{x}^{\phi}(\theta)=\frac{\tau}{\delta} x^{\tau}(\theta)$ (implying an aggregate demand $M^{\phi}=\frac{\tau}{\delta} X^{\tau}$ ) and their gross shortterm funding would be $x^{\phi}(\theta)=x^{\tau}(\theta)+m^{\phi}(\theta)=\frac{\delta+\tau}{\delta} x^{\tau}(\theta)>x^{\tau}(\theta)$ (implying $X^{\phi}=E_{\theta}\left(x^{\phi}(\theta)\right)=X^{\tau}+M^{\phi}=\frac{\delta+\tau}{\delta} X^{\tau}>X^{\tau}$ at the aggregate level). Importantly, the total direct net costs of holding liquidity would cause a deadweight loss of $\delta m^{\phi}(\theta)=\tau x^{\tau}(\theta)$ to each bank. Not surprisingly, the aggregate deadweight loss $\delta M^{\phi}=\tau X^{\tau}$ equals the tax revenue that the replicated tax on short-term funding could have raised.

The presence of the deadweight loss $\tau X^{\tau}$ implies that the liquidity requirement that seemingly replicates the Pigovian solution $\left(\phi^{*}=\frac{\tau^{*}}{\delta+\tau^{*}}\right)$ is not socially efficient. 
Proposition 6. With $\delta>0$, replicating the net short-term funding allocation and aggregate systemic risk of the efficient allocation using a liquidity requirement $\phi^{*}=\frac{\tau^{*}}{\delta+\tau^{*}}$ is feasible but entails a deadweight loss $\tau^{*} X^{*}>0$.

Actually, $\phi^{*}$ will not generally be optimal even from a secondbest perspective, except in the non-generic situation in which the efficient Pigovian tax $\tau^{*}$ happens to be at a critical point of the Laffer curve $\tau X^{\tau}$. This is because moving the liquidity requirement marginally away from $\phi^{*}$ (in one direction) will reduce the deadweight loss $\delta M^{\phi}$, while other components of social welfare will not change (since they are maximized precisely with $\phi=\phi^{*}$ ).

For a given spread $\delta>0$, the socially optimal liquidity requirement will be some $\phi^{S B}=\frac{\tau^{S B}}{\delta+\tau^{S B}}$ whose associated implicit tax rate $\tau^{S B}$ satisfies

$$
\begin{aligned}
& \tau^{S B}=\arg \max _{\tau \geq 0} \int_{0}^{1}\left[\pi\left(x^{\tau}(\theta), \theta\right)-\varepsilon\left(x^{\tau}(\theta), \theta\right) c\left(X^{\tau}\right)-\tau x^{\tau}(\theta)\right] f(\theta) d \theta \\
& \text { s.t.: } \quad x^{\tau}(\theta)=\arg \max _{x} \pi(x, \theta)-\varepsilon(x, \theta) c\left(X^{\tau}\right)-\tau x \text { for all } \theta \\
& \qquad \int_{0}^{1} x^{\tau}(\theta) f(\theta) d \theta=X^{\tau} .
\end{aligned}
$$

This formulation of the optimization problem exploits the analogy explained above, which conveniently allows us to write the deadweight loss suffered by each bank as $\tau x^{\tau}(\theta)$, which is actually independent of $\delta$ and will end up making the solution in terms of $\tau^{S B}$ also independent of $\delta$. The constraints in the optimization problem are simply the conditions that define an equilibrium with a $\operatorname{tax} \tau$ on short-term funding (see section 6).

Typically, the optimal liquidity requirement $\phi^{S B}$ will be inferior to $\phi^{*}$, implying more aggregate systemic risk than in the firstbest allocation. The intuition for this is that moving away from the unregulated equilibrium allocation by increasing $\phi$ will typically monotonically increase the aggregate deadweight loss $\delta M^{\phi}$, while the remaining marginal benefits of moving towards the firstbest allocation decline towards zero as $\phi$ approaches $\phi^{*}$. In fact, for the parameterization behind figures 1 and 2, the optimal liquidity requirement $\phi^{S B}$ is just zero, meaning that the deadweight losses 
associated with forcing banks to hold liquidity do not compensate, for any level of $\phi$, the gains from the reduction in systemic risk. ${ }^{22}$

Interestingly, the writing of the problem as in (20) makes clear that $\tau^{S B}$ does not depend on $\delta$, implying that the total variation of $\phi^{S B}=\frac{\tau^{S B}}{\delta+\tau^{S B}}$ with respect to $\delta$ is just given by the partial derivative

$$
\frac{\partial \phi^{S B}}{\partial \delta}=\frac{-\tau^{S B}}{\left(\delta+\tau^{S B}\right)^{2}}<0 .
$$

Hence, if the regulator wants to implement an interior second-best allocation as defined above (or to seemingly replicate the efficient Pigovian tax), it should be ready to move the imposed liquidity requirement $\phi^{S B}$ (or $\phi^{*}$ ) in response to the fluctuations in the spread $\delta$. In practice, moving $\phi$ and the implied adjustments in quantities may be a source of trouble. On the one hand, authorities will have to be effective in changing $\phi$ in due course. On the other hand, frequent and sudden changes in $\phi$ might produce volatility in the demand for the liquid assets included in $M^{\phi}$. This might be especially so if $\delta$ approaches zero, in which case the prescriptions for $\phi^{S B}$ (or $\phi^{*}$ ) imply that $M^{\phi}$ would tend to infinity.

With potentially large variations in the demand for liquid assets, the reference to possible general equilibrium implications is inexcusable. Our results are definitely valid if the supply of liquid assets is sufficiently elastic at the rate $r_{m}$ used in the definition of the spread $\delta$. However, if changes in liquidity requirements have an impact on the equilibrium value of $r_{m}$ due to a more general interaction between the demand and supply for liquid assets, then the required analysis may well exceed the scope of this paper. This is especially so if $r_{m}$ is also the reference risk-free rate in the economy, because then the net present values captured by our reduced-form value functions might be expected to change with $r_{m}$ and the whole analysis in (at least) this section should be redone using a somewhat more structural formulation.

\footnotetext{
${ }^{22}$ In our example, the liquidity requirement that replicates the effects of the optimal Pigovian tax $\left(\tau^{*}=0.17\right)$ has deadweight costs equivalent to 22 percent of the value generated by banks in the unregulated equilibrium. These costs are more than ten times the increase in welfare that the pure Pigovian solution might produce relative to the unregulated equilibrium.
} 


\section{Risk Shifting and the Case for Quantity Regulation}

In this section we extend the model to address formally one of the main criticisms to the proposal of a Pigovian approach to liquidity risk regulation. Such criticism is based on the "robustness" of the price-based approach to modeling mistakes and, specifically, to the possibility of having some "crazy" or just particularly risk-inclined banks that, for the sake of expanding their risky lending, are willing to pay large amounts of the established tax so as to use large amounts of short-term funding.

In our baseline formulation, banks that like to take more shortterm funding are those that can extract more expected NPV from it. In such a formulation, the considered dimension of heterogeneity makes banks with larger $\theta$ essentially more valuable - privately and, if properly regulated, also socially. We will now denote that dimension of heterogeneity by $\theta_{1}$ and introduce a second dimension of heterogeneity, $\theta_{2} \in[0,1]$, intended to capture differences in banks' inclination towards risk taking. ${ }^{23}$ The joint distribution of $\left(\theta_{1}, \theta_{2}\right)$ will be described by the density function $f\left(\theta_{1}, \theta_{2}\right)$.

To capture heterogeneity in banks' risk-shifting inclinations formally, we are going to treat $\theta_{2}$ as a parameter that determines the fraction of the losses incurred by a bank during a crisis which are not internalized by its owners but passed (without compensation) to other stakeholders (e.g., the deposit insurer). We then assume each bank, when privately deciding on $x$, only considers the fraction $1-\theta_{2}$ of $\varepsilon(x, \theta) c(X)$ as an expected value loss, leaving the remaining fraction $\theta_{2}$ to other stakeholders. Hence, the social welfare measure $W(\{x(\theta)\})$ must now explicitly consider, in addition to the NPV

\footnotetext{
${ }^{23}$ The literature has identified several sources of such differences. Corporate governance arrangements may affect the severity of the conflicts of interest between shareholders and debtholders, making the former more or less capable to ex post expropriate the former by shifting risk (Jensen and Meckling 1976). In the case of banks, risk-shifting problems are exacerbated by the existence of safetynet guarantees (e.g., deposit insurance) provided at risk-insensitive rates. In such a setup, banks' charter values reduce excessive risk taking (Keeley 1990). Capital requirements (especially if risk based) generally improve the alignment of incentives between the bankers and other stakeholders (Holmstrom and Tirole 1997) and can specifically attenuate the risk-shifting problem (Hellmann, Murdock, and Stiglitz 2000; Repullo 2004).
} 
appropriated by the bank owners, the losses $-\theta_{2} \varepsilon(x, \theta) c(X)$ passed on to other bank stakeholders.

So the new objective function for banks is

$$
v\left(x, X, \theta_{1}, \theta_{2}\right)=\pi\left(x, \theta_{1}\right)-\left(1-\theta_{2}\right) \varepsilon\left(x, \theta_{1}\right) c(X),
$$

while social welfare is given by

$$
\begin{aligned}
W\left(\left\{x\left(\theta_{1}, \theta_{2}\right)\right\}\right)= & \int_{0}^{1} \int_{0}^{1}\left[v\left(x\left(\theta_{1}, \theta_{2}\right), X, \theta_{1}, \theta_{2}\right)\right. \\
& \left.-\theta_{2} \varepsilon\left(x\left(\theta_{1}, \theta_{2}\right), \theta_{1}\right) c(X)\right] f\left(\theta_{1}, \theta_{2}\right) d \theta_{1} d \theta_{2},
\end{aligned}
$$

where

$$
X=g\left(\left\{x\left(\theta_{1}, \theta_{2}\right)\right\}\right)=\int_{0}^{1} \int_{0}^{1} x\left(\theta_{1}, \theta_{2}\right) f\left(\theta_{1}, \theta_{2}\right) d \theta_{1} d \theta_{2} .
$$

Plugging (22) into (23), social welfare can be written as

$$
\begin{aligned}
W\left(\left\{x\left(\theta_{1}, \theta_{2}\right)\right\}\right)= & \int_{0}^{1} \int_{0}^{1}\left[\pi\left(x\left(\theta_{1}, \theta_{2}\right), \theta_{1}\right)-\varepsilon\left(x\left(\theta_{1}, \theta_{2}\right), \theta_{1}\right) c(X)\right] \\
& \times f\left(\theta_{1}, \theta_{2}\right) d \theta_{1} d \theta_{2}
\end{aligned}
$$

which is conceptually identical to (3).

\subsection{Gambling as the Sole Source of Heterogeneity}

To highlight our key argument, suppose that the variation due to $\theta_{1}$, whose implications we have already discussed in prior sections, is shut down by fixing $\theta_{1}=\bar{\theta}_{1}$ for all banks. So residual bank heterogeneity is due to $\theta_{2}$ only. How is the unregulated equilibrium determined? And the socially optimal allocation? How do they differ? How should $x\left(\theta_{2}\right)$ be regulated?

Without restating all the relevant definitions (which will follow mechanically from the adaptation of those already presented for the baseline model), the answers to these questions can be found by comparing the first-order conditions satisfied by bank decisions, $x^{e e}\left(\theta_{2}\right)$, and the systemic risk measure, $X^{e e}$, in an interior unregulated equilibrium, with the conditions satisfied by their counterparts, $x^{* *}\left(\theta_{2}\right)$ 
and $X^{* *}$, in an interior socially optimal allocation. Similarly to (5), the unregulated equilibrium objects satisfy

$$
\pi_{x}\left(x^{e e}\left(\theta_{2}\right), \bar{\theta}_{1}\right)-\left(1-\theta_{2}\right) \varepsilon_{x}\left(x^{e e}\left(\theta_{2}\right), \bar{\theta}_{1}\right) c\left(X^{e e}\right)=0,
$$

while, similarly to (9), in the socially optimal allocation we must have

$$
\begin{aligned}
\pi_{x}\left(x^{* *}\left(\theta_{2}\right), \bar{\theta}_{1}\right) & -\varepsilon_{x}\left(x^{* *}\left(\theta_{2}\right), \bar{\theta}_{1}\right) c\left(X^{* *}\right) \\
& -E_{z}\left(\varepsilon\left(x^{* *}(z), \bar{\theta}_{1}\right)\right) c^{\prime}\left(X^{* *}\right)=0,
\end{aligned}
$$

in both cases for all $\theta_{2}$. From these conditions, it is immediate to conclude that $x^{e e}\left(\theta_{2}\right)$ is increasing in $\theta_{2}$ (that is, banks with greater risk-shifting inclinations tend to use more short-term funding) while $x^{* *}\left(\theta_{2}\right)$ is independent of $\theta_{2}$ and, hence, equal to a constant $\bar{x}^{* *}$ (since, for any given $x, \theta_{2}$ determines the distribution of value across bank stakeholders but not the total marginal value of short-term funding).

By simple comparison of the two sets of conditions, it is now obvious that the efficient Pigovian tax schedule is

$$
\tau^{* *}\left(\theta_{2}\right)=\theta_{2} \varepsilon_{x}\left(x^{* *}\left(\theta_{2}\right), \bar{\theta}_{1}\right) c\left(X^{* *}\right)+E_{z}\left(\varepsilon\left(x^{* *}(z), \bar{\theta}_{1}\right)\right) c^{\prime}\left(X^{* *}\right),
$$

where the first term is new relative to (12) and reflects that riskshifting incentives produce additional discrepancies between the private and social costs of expanding banks' short-term funding. In contrast to the pure systemic externality term (identical to what we had in the baseline model), the first term depends on $\theta_{2}$. Hence, the efficient Pigovian tax schedule is not flat and cannot be enforced without detailed knowledge of each bank's risk-shifting inclination. A flat tax on short-term funding will not implement the first-best allocation.

Now, however, proper quantity regulation can do a great job. Specifically, a net stable funding requirement that effectively imposes the first-best quantity $\bar{x}^{* *}$ as a limit to each bank's use of shortterm funding would implement the first best. It is easy to see that the regulatory constraint will be binding for all $\theta_{2}$. As for liquidity requirements, the rather negative conclusions obtained in the baseline analysis would still apply: with $\delta=0$, a liquidity requirement 


\section{Figure 3. Allocations when Banks Differ in Gambling Incentives}

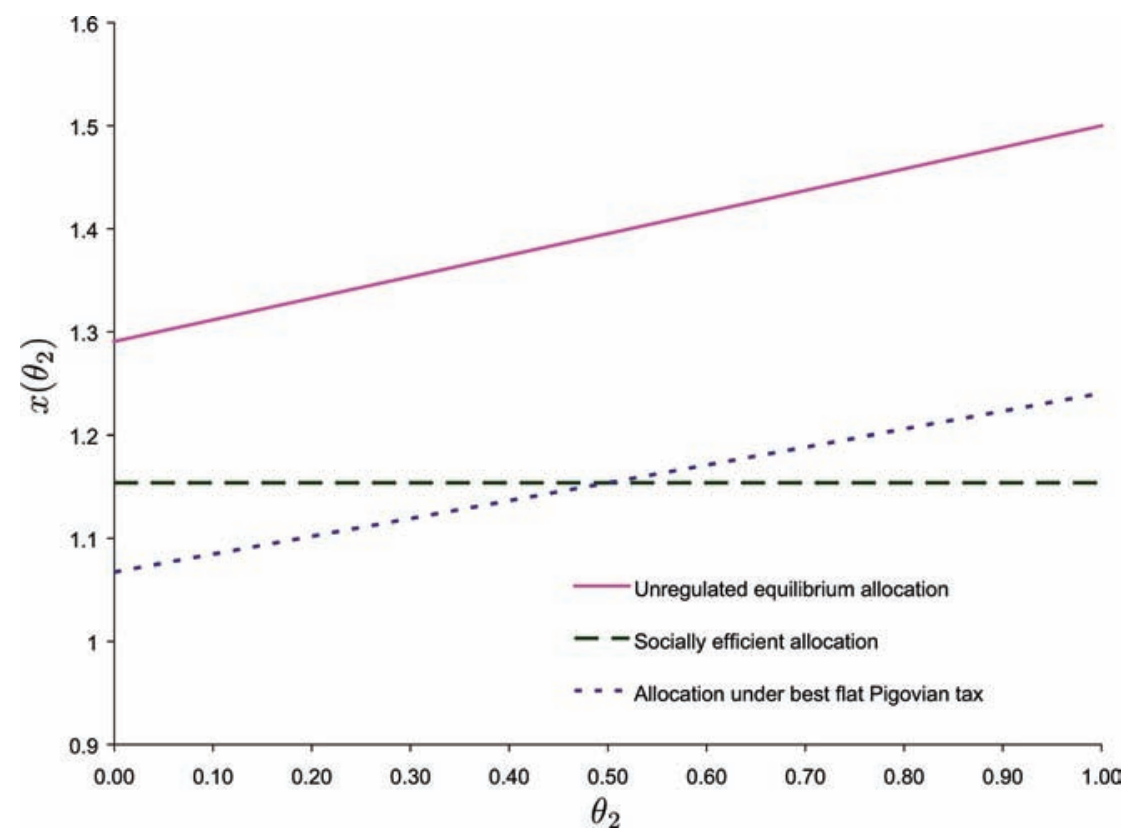

is as ineffective as it was there, while with $\delta>0$ its effect is very similar to (but with worse welfare properties than) a flat tax on short-term funding. And a flat tax on short-term funding is not a good solution in this environment!

Our conclusions can then be summarized as follows:

Proposition 7. If gambling incentives constitute the only source of heterogeneity across banks, a stable funding requirement $\bar{x}=\bar{x}^{* *}$ implements the socially efficient allocation, while no flat-rate tax on short-term funding can do it. A liquidity requirement has the same shortcomings as in the baseline model and is, then, either ineffective (if $\delta=0$ ) or very similar (but with larger deadweight costs) to the flat-rate tax solution (if $\delta>0$ ).

As a graphical illustration of these results, figure 3 develops an example based on extending and modifying the parameterization used in previous figures. We fix $\theta_{1}=1$ and introduce $\theta_{2}$ as in (22) 
under the assumption that it is uniformly distributed over the interval $[0,1]$. The new figure depicts, as a function of $\theta_{2}$, the unregulated equilibrium allocation $x^{e e}\left(\theta_{2}\right)$, the socially optimal allocation $x^{* *}\left(\theta_{2}\right)$ (which can be attained by limiting banks' short-term funding to $\left.\bar{x}^{* *}=1.154\right)$, and the allocation that would arise under the best flat tax on short-term funding. ${ }^{24}$ In this example, social welfare in the unregulated equilibrium is 95.4 percent of its first-best level, while under the flat Pigovian tax it reaches 99.8 percent of the first-best level. This good second-best performance is due to the fact that, as illustrated in the figure, the downward shift in the use of shortterm funding by all banks induced by the flat tax (which corrects for the "average" externalities of the unregulated equilibrium) is of relatively larger importance than the "differences" in externalities produced by the heterogeneity in $\theta_{2}$.

\subsection{Generalizing the Analysis}

The analysis of the general case in which both $\theta_{1}$ and $\theta_{2}$ exhibit significant variation across banks is complicated and unlikely to yield clear-cut analytical results, if anything because first-best efficiency will not be generally attainable using instruments that are not explicitly contingent on $\theta_{1}$ or $\theta_{2}$. The analysis of simple instruments will necessarily be based on their second-best performance, which will have to be checked numerically for the general case.

Using a continuity argument and building on the polar cases already analyzed above, we can say that a flat tax on short-term funding will tend to perform better than a stable funding requirement if $\theta_{1}$ is the dominant source of heterogeneity, i.e., if it has ample variation and, specifically, sufficient density at its upper tail, producing sufficiently many banks with value-generating motives to use short-term funding at a larger scale. The opposite will be true if $\theta_{2}$ is the dominant source of variation, in this case producing sufficiently many banks whose main reason for wanting to use short-term funding at large scale is risk shifting. For instance, if the banking system had a small group of gambling banks and an ample majority

\footnotetext{
${ }^{24}$ In our example, the trade-offs involved in determining the best flat tax rate $\bar{\tau}^{S B}$ are linear, so $\bar{\tau}^{S B}$ (which equals 0.26 ) coincides with the average value of the efficient Pigovian schedule $\tau^{* *}\left(\theta_{2}\right)$ characterized in equation (28).
} 
of non-gambling banks, a stable funding requirement might be helpful to control the otherwise excessive short-term funding that the former would like to use.

But continuing with these easy-to-visualize examples, one can also anticipate possible advantages from combining the instruments. Suppose, in particular, that there is a group of banks which are essentially diverse in $\theta_{1}$ and with no specially severe incentives to gamble, like in our main case, but there are also banks, at the top of the overall unconditional distribution of $\theta_{1}$, which are also heterogeneous in their incentives to gamble (perhaps due to "too-big-to-fail" problems and bail-out expectations). Then, in addition to having a tax on short-term funding that graduates the contribution to systemic externalities of the banks in the non-gambling group (and also, though imperfectly, the banks in the gambling group), it might be socially valuable to introduce a complementary quantitative limit on short-term funding (say, via a stable funding requirement) so as to further control the externalities caused by the group of gambling banks.

\section{Dealing with Systemic Importance}

Suppose that factors such as size, interconnectedness, lack of substitutability, global (cross-jurisdictional) activity, and complexity make some banks more "systemically important" than others in the very sense that the per-unit contribution of their short-term funding to the systemic risk measure $X$ is larger than for other banks. Suppose in particular that systemic importance is captured by a new dimension of heterogeneity, $\theta_{3}$, which only enters significantly into the equations of the economy through the following extended measure of systemic risk:

$$
X=\int_{0}^{1} \int_{0}^{1} w\left(\theta_{3}\right) x\left(\theta_{1}, \theta_{3}\right) f\left(\theta_{1}, \theta_{3}\right) d \theta_{1} d \theta_{3},
$$

where $w\left(\theta_{3}\right)$ is the systemic risk weight of the banks of class $\theta_{3}$ and $x\left(\theta_{1}, \theta_{3}\right)$ denotes the short-term funding used by banks characterized by the pair $\left(\theta_{1}, \theta_{3}\right)$. This quantity is written as a function $\theta_{3}$ to account for the possibility that regulation is made contingent on $\theta_{3}$ and, through it, systemic importance has an impact on the short-term funding used by each bank. 
Extending our characterization of competitive equilibria (unregulated or with taxes) and the socially optimal allocation to deal with this case is immediate. Moreover, it can be shown that decentralizing the socially optimal allocation as a competitive equilibrium with taxes will only require setting $\tau\left(\theta_{3}\right)=w\left(\theta_{3}\right) \tau^{*}$, where $\tau^{*}=E_{z}\left(\varepsilon\left(x^{*}(z), z\right)\right) c^{\prime}\left(X^{*}\right)$ is a reference rate set exactly like in (12), except $z$ should now be interpreted as the vector $\left(z_{1}, z_{3}\right)$ of individual bank characteristics. So the presence of heterogenous systemic importance calls for considering each bank's systemic importance measure $w\left(\theta_{3}\right)$ as a scaling factor for the reference (flat) tax rate $\tau^{*} .^{25}$ Importantly, the optimal Pigovian tax rate $\tau\left(\theta_{3}\right)$ preserves the key property of being not directly dependent on the individual value of each bank's lending opportunities as measured by $\theta_{1}$.

\section{Conclusions}

We have developed a formal analysis of the relative performance of realistic price-based and quantity-based approaches to the regulation of systemic externalities associated with banks' short-term funding. The analysis suggests that if the return to the lending (or investment) activities undertaken by the banks using this funding is heterogeneously distributed across banks (or, similarly, over time), a Pigovian tax on short-term funding will dominate a net stable funding ratio or a liquidity coverage ratio. If some (poorly capitalized or low charter value) banks have strong gambling incentives and expand their activity as a way to shift risk to outside stakeholders (e.g., the deposit insurer), quantity requirements may have better properties. In general terms, an optimal regulatory design may combine priceand quantity-based instruments, and the emphasis on each of them will depend on what is the dominant dimension of heterogeneity across banks (or variation over time).

Going beyond the pure regulation of short-term funding, capital requirements - the most important regulatory instrument in banking - can be seen as a way to directly influence gambling incentives (and the extent to which banks differ in this dimension).

\footnotetext{
${ }^{25}$ On June 25, 2011 the BCBS issued a press release announcing progress on a consultative document containing a methodology for assessing systemic importance.
} 
Strengthening capital requirements, by ensuring shareholders internalize a larger part of the lower tail of the returns generated by the banks, will tend to produce a smaller measure of banks with strong inclinations for risk shifting. In this sense, our results suggest that in a scenario with stronger capital regulation, such as that envisaged after the full implementation of Basel III, there will be even greater room for having a Pigovian-style tax, levy, or charge on short-term funding as part of the second-best regulatory mix.

\section{References}

Acharya, G., D. Gale, and T. Yorulmazer. 2011. "Rollover Risk and Market Freezes." Journal of Finance 66 (4): 1177-1209.

Acharya, V., and O. Merrouche. 2010. "Precautionary Hoarding of

Liquidity and Inter-Bank Markets: Evidence from the Sub-prime

Crisis." NBER Working Paper No. 16395.

Acharya, V., and S. Öncü. 2010. "The Repurchase Agreement (Repo)

Market." In Regulating Wall Street: The Dodd-Frank Act and the

New Architecture of Global Finance, ed. V. Acharya, T. Cooley,

M. Richardson, and I. Walters, 319-50 (Chapter 11). Wiley.

Acharya, V., L. Pedersen, T. Philippon, and M. Richardson. 2010.

"Measuring Systemic Risk." Federal Reserve Bank of Cleveland Working Paper No. 10-02.

Acharya, V., and S. Viswanathan. 2011. "Leverage, Moral Hazard, and Liquidity." Journal of Finance 66 (1): 99-138.

Adrian, T., and M. Brunnermeier. 2008. "CoVaR." Federal Reserve Bank of New York Staff Report No. 348.

Allen, F., A. Babus, and E. Carletti. 2010. "Financial Connections and Systemic Risk." NBER Working Paper No. 16177.

Allen, F., and D. Gale. 2000. "Financial Contagion." Journal of Political Economy 108 (1): 1-33.

Basel Committee on Banking Supervision. 2010. "Basel III: International Framework for Liquidity Risk Measurement, Standards and Monitoring." Bank for International Settlements (December).

Brunnermeier, M. 2009. "Deciphering the Liquidity and Credit Crunch 2007-2008." Journal of Economic Perspectives 23 (1): $77-100$.

Brunnermeier, M., and M. Oehmke. Forthcoming. "The Maturity Rat Race." Forthcoming in Journal of Finance. 
Calomiris, C., and C. Kahn. 1991. "The Role of Demandable Debt in Structuring Optimal Banking Arrangements." American Economic Review 81 (3): 497-513.

Diamond, D., and P. Dybvig. 1983. "Bank Runs, Deposit Insurance, and Liquidity." Journal of Political Economy 91 (3): 401-19.

Diamond, D., and R. Rajan. 2001. "Liquidity Risk, Liquidity Creation and Financial Fragility: A Theory of Banking." Journal of Political Economy 109 (2): 287-327.

Farhi, E., and J. Tirole. 2010. "Collective Moral Hazard, Maturity Mismatch and Systemic Bailouts." Forthcoming in American Economic Review.

Financial Services Authority. 2009. Strengthening Liquidity Standards. Policy Statement No. 09/16 (October).

Glaeser, E., and A. Shleifer. 2001. "A Reason for Quantity Regulation." American Economic Review: Papers and Proceedings 91 (2): 431-35.

Gorton, G. 2009. "Slapped in the Face by the Invisible Hand: Banking and the Panic of 2007." Paper prepared for the Federal Reserve Bank of Atlanta's 2009 Financial Markets Conference: Financial Innovation and Crisis, Jekyll Island, Georgia, May 1113.

Gorton, G., and A. Metrick. 2010. "Regulating the Shadow Banking System." Brookings Papers on Economic Activity 41 (2): 261-312.

Hellmann, T., K. Murdock, and J. Stiglitz. 2000. "Liberalization, Moral Hazard in Banking, and Prudential Regulation: Are Capital Requirements Enough?" American Economic Review 90 (1): 147-65.

Holmstrom, B., and J. Tirole. 1997. "Financial Intermediation, Loanable Funds, and the Real Sector." Quarterly Journal of Economics 112 (3): 663-91.

Huang, R., and L. Ratnovski. 2011. "The Dark Side of Bank Wholesale Funding." Journal of Financial Intermediation 20 (2): 24863.

Huberman, G., and R. Repullo. 2010. "Moral Hazard and Debt Maturity." Mimeo, CEMFI.

Jeanne, O., and A. Korinek. 2010. "Managing Credit Booms and Busts: A Pigouvian Taxation Approach." NBER Working Paper No. 16377. 
Jensen, M., and W. Meckling. 1976. "Theory of the Firm: Managerial Behavior, Agency Costs and Ownership Structure." Journal of Financial Economics 3 (4): 305-60.

Kaplow, L., and S. Shavell. 2002. "On the Superiority of Corrective Taxes to Quantity Regulation." American Law and Economics Review 4 (1): 1-17.

Keeley, M. C. 1990. "Deposit Insurance, Risk, and Market Power in Banking." American Economic Review 80 (5): 1183-1200.

Keeton, W. 1990. "Risk-Based Deposit Insurance: Is Price Regulation Necessarily Better than Quantity Regulation?" In Game Plans for the '90s, 44-61. Proceedings of the 26th Annual Conference on Bank Structure and Competition, Federal Reserve Bank of Chicago, May 9-11.

Laeven, L., and F. Valencia. 2010. "Resolution of Banking Crises: The Good, the Bad, and the Ugly." IMF Working Paper No. $10 / 146$.

Lorenzoni, G. 2008. "Inefficient Credit Booms." Review of Economic Studies 75 (3): 809-33.

Martin, A., D. Skeie, and E. L. von Thadden. 2010. "Repo Runs." Mimeo, University of Mannheim.

Perotti, E., and J. Suarez. 2009. "Liquidity Insurance for Systemic Crises." CEPR Policy Insight No. 31 (February).

Poole, W. 1970. "Optimal Choice of Monetary Policy Instruments in a Simple Stochastic Macro Model." Quarterly Journal of Economics 84 (2): 197-216.

Repullo, R. 2004. "Capital Requirements, Market Power, and RiskTaking in Banking." Journal of Financial Intermediation 13 (2): 156-82.

Rochet, J.-C., and X. Vives. 2004. "Coordination Failures and the Lender of Last Resort: Was Bagehot Right After All?" Journal of the European Economic Association 2 (6): 1116-47.

Segura, A., and J. Suarez. 2011. "Dynamic Maturity Transformation." Mimeo, CEMFI.

Wagner, W. 2010. "Diversification at Financial Institutions and Systemic Crises." Journal of Financial Intermediation 19 (3): 37386.

Weitzman, M. L. 1974. "Prices vs. Quantities." Review of Economic Studies 41 (4): 477-91. 